\title{
Fistula between the Jejunum and the Inferior Vena Cava after Esophagojejunal Anastomosis
}

\author{
Young S. Oh ${ }^{\mathrm{a}}$ Paul M. Knechtges ${ }^{\mathrm{b}}$ \\ aDivision of Gastroenterology and Hepatology and bepartment of Radiology, \\ Medical College of Wisconsin, Milwaukee, Wisc., USA
}

\section{Key Words}

Esophageal cancer $\cdot$ Fistula $\cdot$ Sepsis $\cdot$ Surgical anastomosis

\begin{abstract}
Fistulas between the luminal gastrointestinal tract and vascular structures can result from a variety of etiologies. While there have been reports of fistulas between the inferior vena cava and the duodenum, we report the first case to our knowledge of a fistula between the jejunum and the inferior vena cava after esophagojejunal anastomosis for recurrent esophageal adenocarcinoma.
\end{abstract}

\section{Introduction}

A fistula is defined as an abnormal communication between two epithelialized surfaces. Fistulas can occur between the luminal gastrointestinal tract and multiple organs including the skin, aorta, biliary system, pericardium, and pancreas.

Previously published cases of fistulas between the small intestine and the inferior vena cava have involved the duodenum [1-15]. Duodenocaval fistulas have been reported in the setting of foreign body ingestion, peptic ulcer disease, penetrating abdominal injury, migrated inferior vena cava filters, as well as following liver transplantation and surgical resection with or without subsequent radiation therapy [1-15]. However, fistulas from the jejunum to the inferior vena cava have not been previously described to our knowledge. A case of a jejunocaval fistula occurring after esophagojejunal anastomosis is presented.

\section{Case Report}

The patient was a 49-year-old male with a history of peptic ulcer disease status post Billroth I anastomosis and vagotomy at the age of 18 who presented with esophageal dysphagia and weight loss. Upper endoscopy demonstrated adenocarcinoma at the gastroesophageal junction. The patient 
underwent resection of the distal esophagus and proximal stomach with esophagogastric anastomosis, at which time stage IIIA disease was found.

Approximately one month after surgery, the patient complained of recurrent esophageal dysphagia, regurgitation of bilious material, and chest pain. Upper endoscopy demonstrated Los Angeles grade D esophagitis with narrowing of the esophagogastric anastomosis, for which balloon dilation was performed to $12 \mathrm{~mm}$. A decision was made to perform a completion gastrectomy with Roux-en-Y esophagojejunal anastomosis due to the refractory stricture at the esophagogastric anastomosis despite three additional attempts at endoscopic dilation as well as persistent regurgitation and chest pain. Despite a preoperative positron emission tomography-computed tomography showing no activity beyond the esophagogastric anastomosis, metastatic adenocarcinoma to the mesentery was found intraoperatively.

Ten days after being discharged from the hospital, the patient was readmitted with sepsis from Enterococcus faecium and Staphylococcus epidermidis bacteremia as well as Candida dubliniensis fungemia. A limited upper gastrointestinal series demonstrated several leaks at the anastomosis (fig. 1). Computed tomography of the chest demonstrated high-density material and air within the inferior vena cava and right atrium suspicious for a fistula between the jejunum and the inferior vena cava (fig. 2) as well as lung nodules consistent with septic emboli (ig. 3 ).

After discussions with the patient and his physicians regarding the potential risk of air embolism, upper endoscopy was performed that demonstrated two fistulous openings at the esophagojejunal anastomosis with clotted blood seen at one of the openings ( $\underline{\text { fig. }} 4$ ). A $1.5-\mathrm{cm}$ fistula between the jejunum and the inferior vena cava was identified perioperatively, for which the patient underwent esophageal diversion, resection of the fistula, and pericardial patch repair of the inferior vena cava after being placed on hypothermic circulatory arrest. The patient's postoperative course was complicated by pulmonary emboli and chylothorax requiring thoracic duct ligation. Adjuvant chemotherapy was considered but was not started due to the patient's declining performance status. He passed away six months after repair of the jejunocaval fistula.

\section{Discussion}

This is the first reported case to our knowledge of a fistula between the jejunum and the inferior vena cava. Overt gastrointestinal bleeding $[1,2,6,7,9,11,13]$, abdominal pain [1-4, 13-15], as well as bacteremia and/or fungemia [1,3-5, 8, 9, 11, 13-15] have been reported in patients with duodenocaval fistulas. While this patient presented with bacteremia and fungemia, he did not have overt gastrointestinal bleeding possibly due to the blood clot that had formed on the jejunal side of the fistula as seen endoscopically.

Air embolism has been reported after upper endoscopy in a patient with a duodenocaval fistula [11]. Therefore, this risk should be considered prior to performing endoscopic procedures in patients with a suspected or confirmed fistula between the luminal gastrointestinal tract and the inferior vena cava.

The presence of a fistula from the small intestine to the inferior vena cava should be considered in the appropriate clinical setting. Timely diagnosis through appropriate diagnostic testing is important for proper management.

\section{Disclosure Statement}

Dr. Oh is a consultant for Boston Scientific Corporation. Dr. Knechtges has no disclosures. 


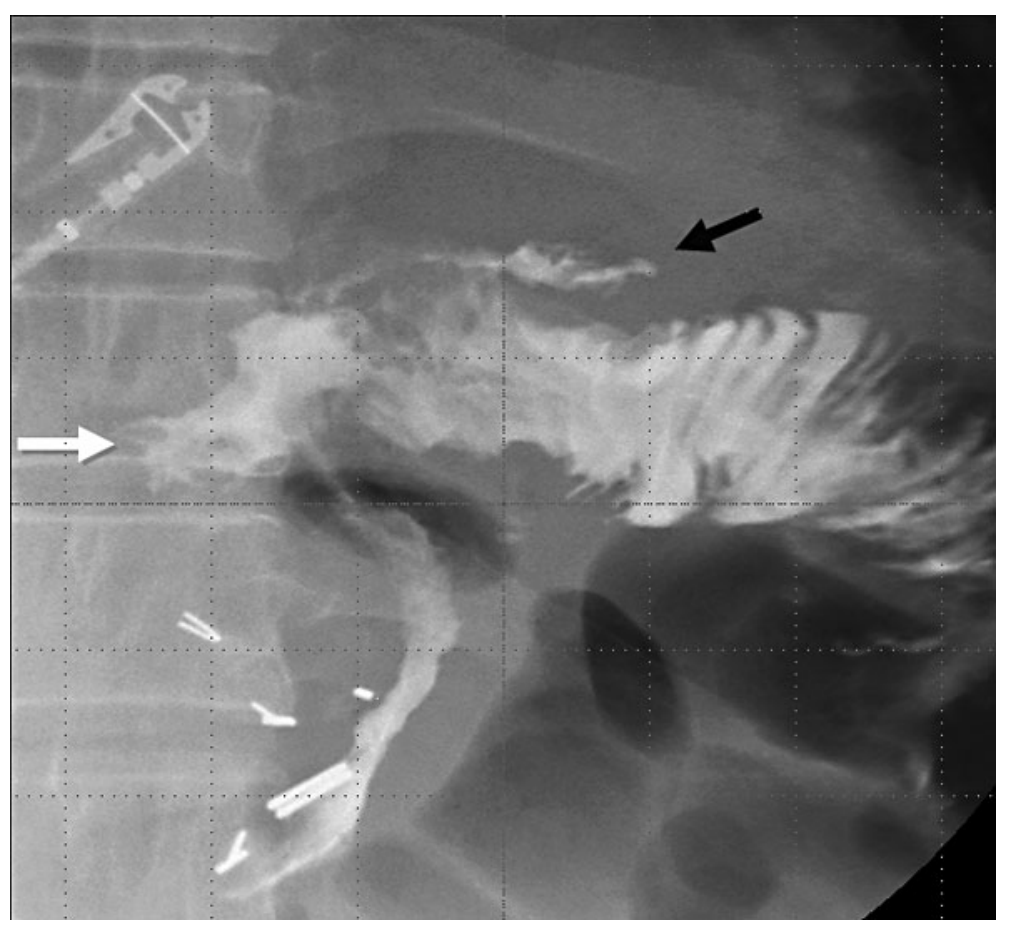

Fig. 1. Limited upper gastrointestinal series demonstrating leaks from the esophagojejunal anastomosis progressing toward the inferior vena cava (white arrow) and collecting under the left hemidiaphragm (black arrow). 


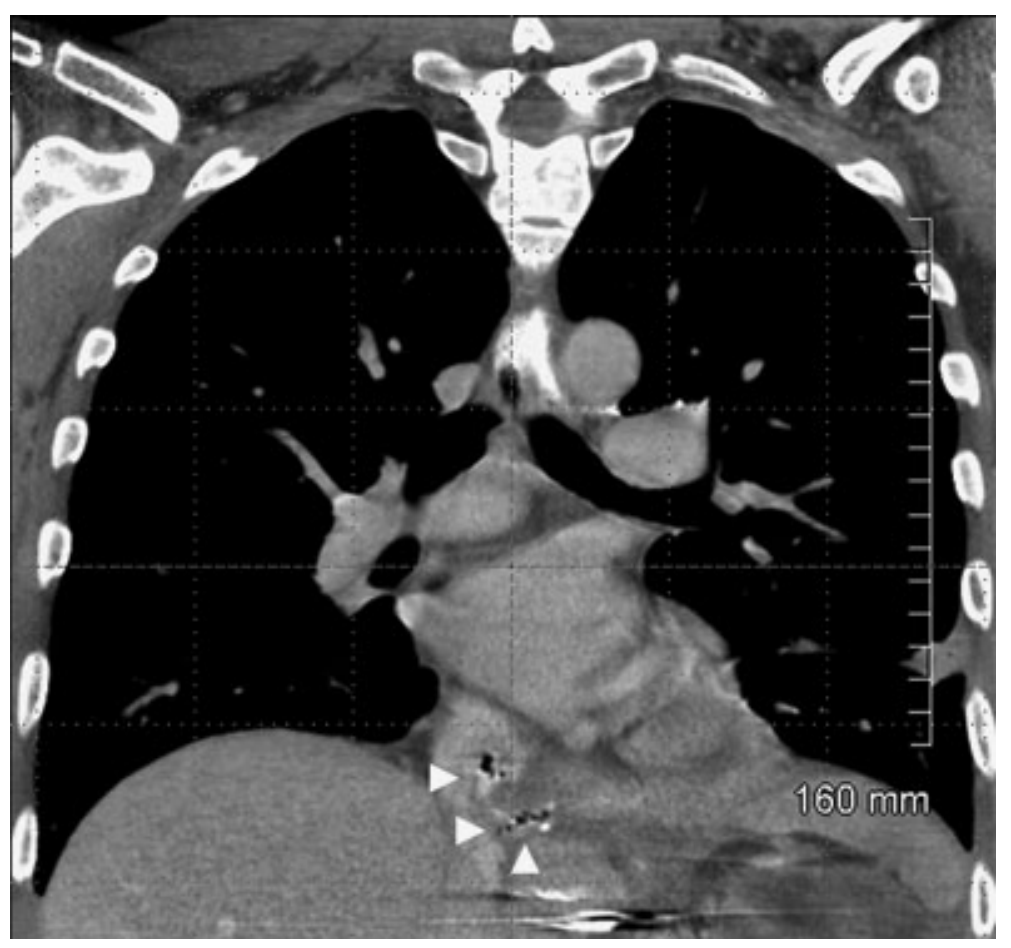

Fig. 2. Computed tomography of the chest showing a fistulous communication between the jejunum/Roux limb and the inferior vena cava (white arrowheads). 


\begin{tabular}{r|l|l|l}
$\begin{array}{r}\text { Case Reports in } \\
\text { Gastroenterology }\end{array}$ & $\begin{array}{l}\text { Case Rep Gastroenterol 2011;5:546-552 } \\
\text { Dol: 10.1159/000331863 }\end{array}$ & $\begin{array}{l}\text { Published online: } \\
\text { September 13, 2011 }\end{array}$ & $\begin{array}{l}\text { O 2011 S. Karger AG, Basel } \\
\text { ISSN 1662-0631 } \\
\text { www.karger.com/crg }\end{array}$ \\
\hline
\end{tabular}

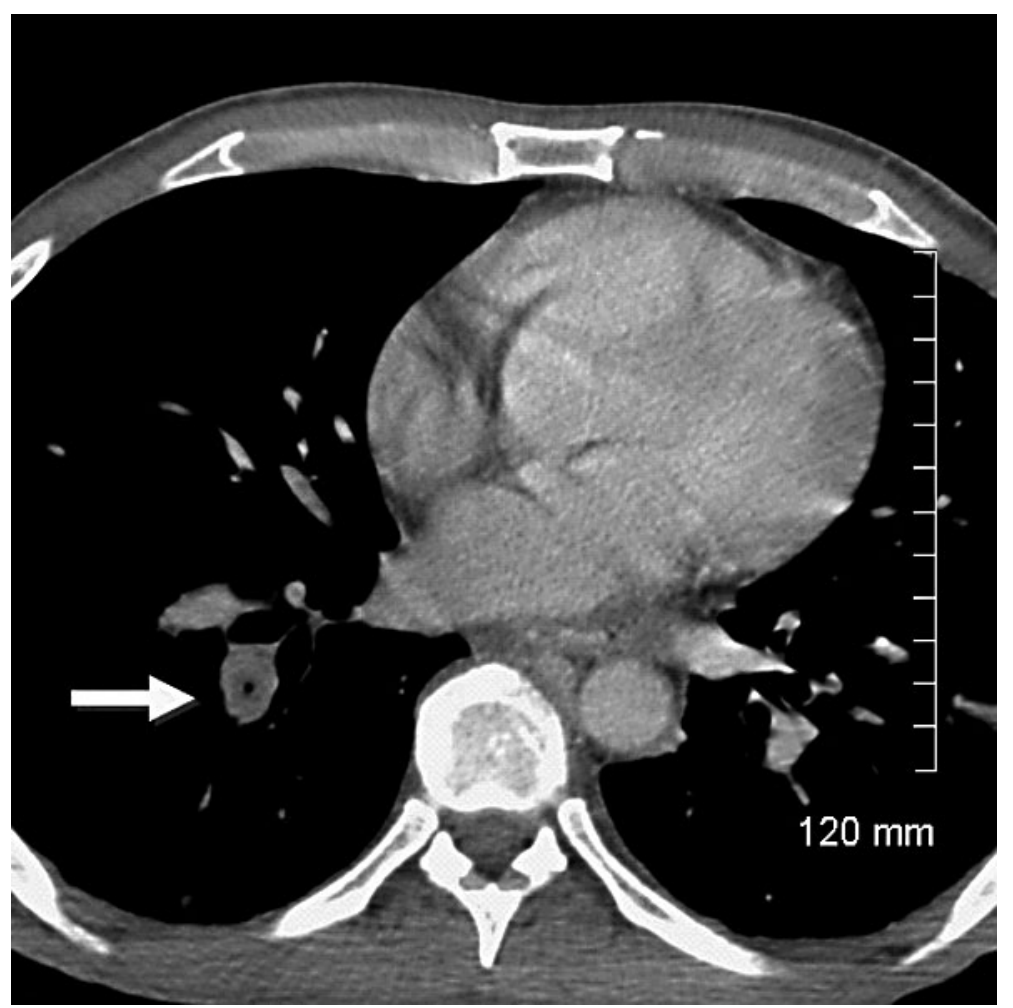

Fig. 3. Computed tomography of the chest showing a gas-containing septic embolus in the right lower lobe (white arrow). 


\begin{tabular}{|c|c|c|c|}
\hline $\begin{array}{r}\text { Case Reports in } \\
\text { Gastroenterolooy }\end{array}$ & $\begin{array}{l}\text { Case Rep Gastroenterol 2011;5:546-552 } \\
\text { DOI: } 10.1159 / 000331863\end{array}$ & $\begin{array}{l}\text { Published online: } \\
\text { September 13, } 2011\end{array}$ & $\begin{array}{l}\text { () } 2011 \text { S. Karger AG, Basel } \\
\text { ISSN } 1662-0631 \\
\text { www.karger.com/crg }\end{array}$ \\
\hline
\end{tabular}

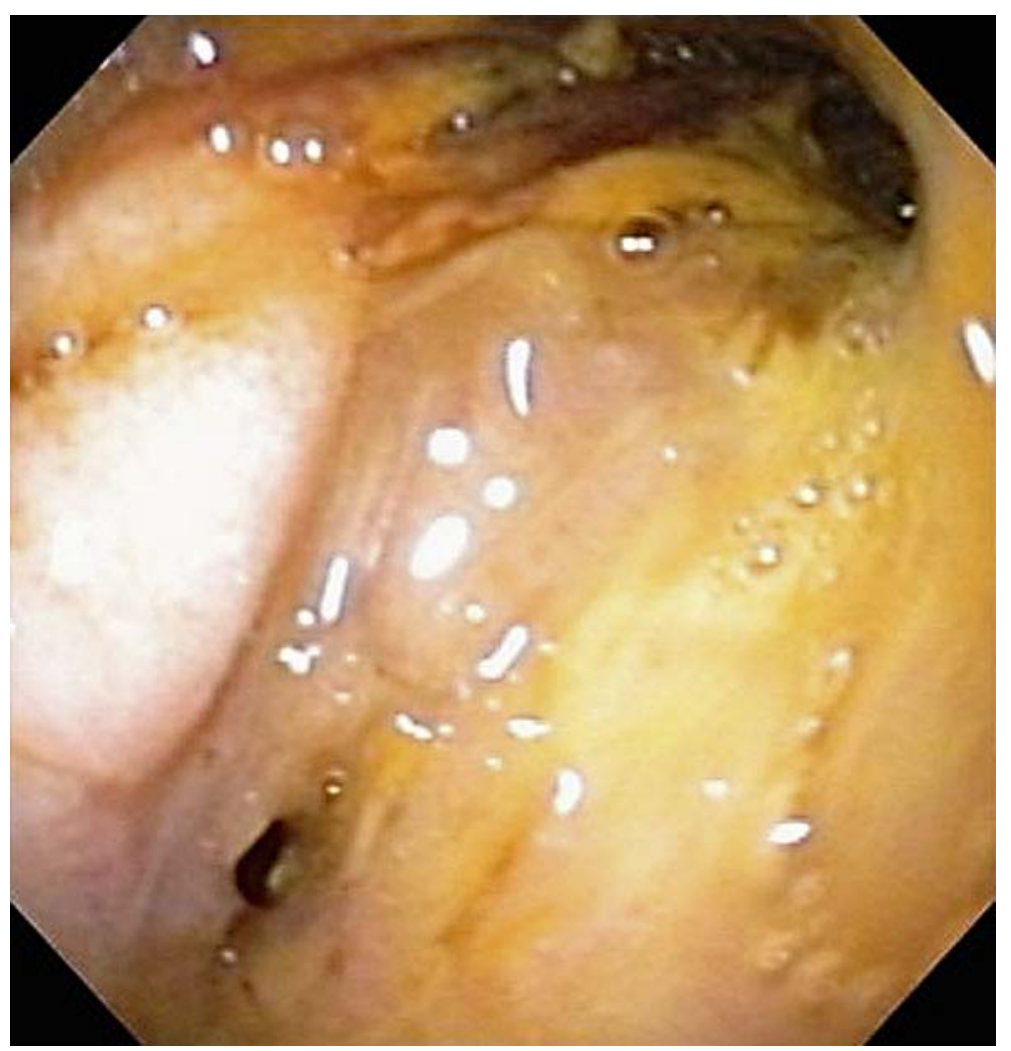

Fig. 4. Upper endoscopy demonstrating two fistulas at the esophagojejunal anastomosis with clotted blood seen at one of the openings.

\section{References}

1 Guillem PG, Binot D, Dupuy-Cuny J, Laberenne JE, Lesage J, Triboulet JP, Chambon JP: Duodenocaval fistula: A life-threatening condition of various origins. J Vasc Surg 2001;33:643-645.

2 Benjamin DS, Ruckle HC, Hadley HR: Local recurrence of renal cell carcinoma causing duodenal-inferior vena caval fistula: case report and review of the literature. Urology 1996;48:636-638.

-3 Guo Y, Zhang YQ, Lin W: Radiologic diagnosis of duodenocaval fistula: a case report and literature review. World J Gastroenterol 2010;16:2314-2316.

4 Brandão D, Canedo A, Maia M, Ferreira J, Vaz G: Duodenocaval fistula as a result of a fish bone perforation. J Vasc Surg 2010;51:1276-1278.

5 Moran EA, Porterfield JR Jr, Nagorney DM: Duodenocaval fistula after irradiation and resection of a retroperitoneal sarcoma. J Gastrointest Surg 2008;12:776-778.

-6 Chan SC, Fan ST, Lo CM, Liu CL, Wong J: Toward current standards of donor right hepatectomy for adult-to-adult live donor liver transplantation through the experience of 200 cases. Ann Surg 2007;245: 110-117.

7 Perera GB, Wilson SE, Barie PS, Butler JA: Duodenocaval fistula: a late complication of retroperitoneal irradiation and vena cava replacement. Ann Vasc Surg 2004;18:52-58.

${ }_{8}$ Rioux M, Lacourciere L, Langis P, Rouleau M: Sonographic detection of ingested foreign bodies in the inferior vena cava. Abdom Imaging 1997;22:108-110.

9 Lesho EP, LeBrun C, Landry FJ, Tsuchida A, Cooper RH: Fatal duodenocaval fistula caused by peptic ulcer. South Med J 1996;89:925-926.

10 Miller CA, Melvin WS: Duodenocaval fistula complicating peptic ulcer disease: case report and review of the literature. Surgery 1996;119:718-719. 
11 Christl SU, Scheppach W, Peters U, Kirchner T: Cerebral air embolism after gastroduodenoscopy: complication of a duodenocaval fistula. Gastrointest Endosc 1994;40:376-378.

-12 O’Keefe GE, Procyshyn AW: Duodenocaval fistulas. Can J Surg 1992;35:347-349.

13 Geraghty JG, Coveney E, Kennedy TE, O’Dwyer PJ, Murphy JJ: Duodenocaval fistula in peptic ulceration. Gut 1991;32:452-453.

14 Schwartz JT, Graham DY: Toothpick perforation of the intestines. Ann Surg 1977;185:64-66.

15 Allen B, Krupski WC, Wylie EJ: Toothpick perforation of the inferior vena cava. West J Med 1983;138: $727-730$. 